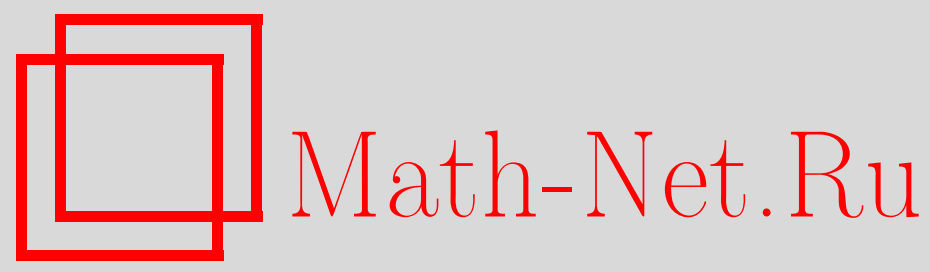

Ю. В. Покорный, Т. В. Белоглазова, К. П. Лазарев, Об одном классе разнопорядковых обыкновенных дифференциальных уравнений на графе, Матем. заметки, 2003, том 73, выпуск 3, 469-470

DOI: https://doi.org/10.4213/mzm620

Использование Общероссийского математического портала Math-Net.Ru подразумевает, что вы прочитали и согласны с пользовательским соглашением http://www . mathnet.ru/rus/agreement

Параметры загрузки:

IP : 3.91 .87 .62

26 апреля 2023 г., 07:49:55

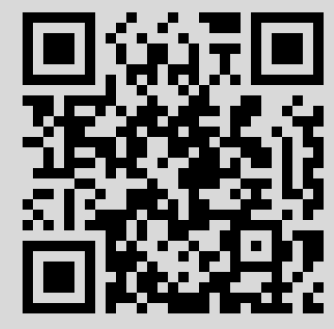




\title{
ОБ ОДНОМ КЛАССЕ РАЗНОПОРЯДКОВЫХ ОБЫКНОВЕННЫХ ДИФ ЕРЕНЦИАЛЬНЫХ УРАВНЕНИЙ НА ГРАФЕ
}

\author{
Ю. В. Покорный, Т. В. Белоглазова, К. П. Лазарев
}

Задачи Штурма-Лиувилля для уравнения второго порядка на геометрических графах достаточно хорошо изучены (см., например, [1]-[5], где получены аналоги теорем Штурма, изучена неосцилляция и спектральная задача). Такие задачи возникают при описании упругих колебаний системы, образованной из скрепленных между собой струн. Для систем из стержней, описьваемых уравнениями четвертого порядка на произвольных графах, получены более скромные результаты [6]. В частных случаях осцилляционность спектра задач для цепочки стержней установлена в [7]-[10], а для цепочки стержней и струн в [8]. В данной работе рассматривается модельная задача для системы из стержней и струн с циклом.

1. Плоская упругая система образована треугольником, составленным из шарнирно-сочленненых стержней, растянутого за вершины тремя конечными струнами. Обозначая всю геометрическую конфигурацию через $\Gamma$ и точки $\Gamma$ через $x$, рассмотрим множество непрерьвных на $\Gamma$ скалярнозначных функций $u: \Gamma \rightarrow \mathbb{R}$. Среди них мы будем искать одномерные поперечные отклонения исходной физической системы.

Будем считать заданными на $Г$ непрерьвную функцию $f(x)$ и достаточно гладкие внутри ребер функции $p(x)$ и $q(x)$, причем внутри ребер треугольника $p(x)>0, q(x)=0$, а на остальных ребрах $p(x)=0, q(x)>0$. Тогда на ребрах треуголника отклонение стержней определяется уравнением $\left(p u^{\prime \prime}\right)^{\prime \prime}=f$, а на остальных ребрах отклонение струн - уравнением $-\left(q u^{\prime}\right)^{\prime}=f$. Это можно записать в виде

$$
\left(p u^{\prime \prime}\right)^{\prime \prime}-\left(q u^{\prime}\right)^{\prime}=f .
$$

Вершины фигуры $\Gamma$, отличные от вершин треугольников, естественно считать границей $Г$ и обозначать через $\partial Г$. Здесь имеет место условие Дирихле

$$
\left.u\right|_{\partial \Gamma}=0 .
$$

Пусть $a$ - какая либо из вершин треугольника. Если $\gamma$ - какое либо из ребер, примькающее к $a$ (их множество обозначается через $\Gamma(a)$ ) и $u_{\gamma}-$ сужение на $\gamma$ функции $u: \Gamma \rightarrow \mathbb{R}$, то крайними для $a$ значениям $и$ функции $u_{\gamma}$ и ее производных мы назьваем предельные значения $u(x), u^{\prime}(x), \ldots$ в точке $a+0$ при параметризации $\gamma$ "от а", т.е. внутрь ребра $\gamma$. Задание уравнения (1) ввиду четности порядка не зависит от ориентации ребер $\Gamma$. Точно также не требует ориентации и условие непрерьвности $u$. Однако без подобных ориентаций не может обойтись важнейшее физическое условие баланса напряжений

$$
\sum_{\gamma \in \Gamma(a)}\left[\left(p_{\gamma} u_{\gamma}^{\prime \prime}\right)^{\prime}-q_{\gamma} u_{\gamma}^{\prime}\right](a+0)=0, \quad u_{\gamma_{1}}^{\prime \prime}(a+0)=u_{\gamma_{2}}^{\prime \prime}(a+0)=0,
$$

где $\gamma_{1}, \gamma_{2}$ - примыкающие к $а$ стороны треугольника. Будем условия (3) относить к решениям исходной задачи вместе с условиями непрерывности, оставляя роль краевых условий равенствам (2).

Нас будут интересовать свойства решений задачи (1)-(3), связанные не только с ее разрешимостью, но и со знаками решений, знаком функции Грина и некоторыми свойствами соответствующей спектральной задачи.

2. Мы назьваем задачу (1)-(3) невырожденной, если она однозначно разрешима при любых $f \in C(\Gamma)$. Невырожденность эквивалентна следующему утверждению.

Теорема 1. Соответствующая однородная задача (1)-(3) имеет только тривиальное на Г решение $u \equiv 0$.

Работа выполнена при поддержке Российского фонда фундаментальных исследований, гранты № 01-01-00418, № 01-01-00417, № 02-01-00307, Минобразования РФ (КЦ СПбГУ), грант № Е001.0-154, и программы “Университеты России”, грант № УР.04.01.047. 
СлЕДСтвиЕ 1. Множество решений однородной задачи (1), (3) (без условий на әГ) трехмерно.

СледствиЕ 2. Существует единственная непрерывная на $Г \times \Gamma$ функция $G(x, s)$ такая, что решение системы (1)-(3) вырахается формулой

$$
u(x)=\int_{\Gamma} G(x, s) f(s) d s
$$

$(G(x, s)-$ функиия Грина задачи (1)-(3)).

Теорема 2. Функиия Грина $G(x, s)$ задачи (1)-(3) неотрицательна на $(\Gamma \times \Gamma)$.

3. Обозначим через $L u$ оператор, действующий на функциях $u: \Gamma \rightarrow \mathbb{R}$, удовлетворяющих условиям (2), (3), по правилу $L u \equiv\left(p u^{\prime \prime}\right)^{\prime \prime}-\left(q u^{\prime}\right)^{\prime}$. Тогда задачу (1)-(3) можно записать в виде

$$
L u=f,
$$

и нас интересует спектральная задача

$$
L u=\lambda m u, \quad m>0 .
$$

Теорема 3. Весь спектр задачи (4) вещественен и наименьшее по модулю собственное значение строго полохительное и простое (т.е. имеет единственную, причем одномерную, корневую чепочку).

4. Рассмотрим теперь нелинейную спектральную задачу

$$
L u=\lambda f(u) .
$$

Пусть $f(0)=0$ и $f(u)$ вогнута по $u$ в том смысле, что $f(\lambda u)>\lambda f(u)$ при $(0<\lambda<1)$ (см. [11]).

Tеорема 4. Пусть $f(u)$ строго возрастает по $u$. Тогда существует интервал $\left(\lambda_{0}, \lambda_{1}\right)$ такой, что для любого $\lambda \in\left(\lambda_{0}, \lambda_{1}\right)$ сущ, ествует единственная собственная функи, $u_{\lambda}(x)$ задачи (5), причем $u_{\lambda}$ строго возрастает по $\lambda$.

\section{СПИСОК ЦИТИРОВАННОЙ ЛИТЕРАТУРЫ}

1. Пенкин О.М., Покорный Ю. В., Провоторова Е. Н. // Краевые задачи. Пермп, 1983. С. 64-70. 2. Пенкин О. М., Покорный Ю. В. // Дифференц. уравнения. 1988. Т. 24. № 4. С. 701-703. 3. Покорный Ю. В., Пенкин О. М. // Докл. АН СССР. 1989. Т. 309. №6. С. 1306-1308. 4. Покорный Ю. В., Пенкин О. М. // Дифференц. уравнения. 1989. Т. 25 . № 7. С. 1141-1190. 5. Покорный Ю. В. // Дифференц. уравнения. 2001. Т. 37. № 5. С. 661-671. 6. Боровских А.В., Мустафокулов Р., Лазарев К.П., Покорный Ю. В. // Докл. РАН. 1995. Т. 345. №6. С. 730-732. 7. Покорный Ю. В., Лазарев К. П. // Дифференц. уравнения. 1987. Т. 23. № 4. С. 658-670. 8. Лазарев К. П. О спектре некоторых негладких многоточечных задач. Дисс. .. . к.ф.-м.н. Воронеж: ВГУ, 1988. 9. Покорный Ю. В., Мустафокулов Р. // Дифференц. уравнения. 1997. Т. 33. № 10. С. 1358-1365. 10. Покорный Ю. В., Мустафокулов Р. // Изв. вузов. Матем. 1999. Т. 441. № 2. С. 75-82. 11. Красносельский М. А. Положительные решения операторных уравнений. М.: Физматгиз, 1962. 